\section{GP167 TRENDS IN INJURY RELATED FATALITIES IN THE IRISH PAEDIATRIC POPULATION: A REVIEW OF NATIONAL MORTALITY DATA}

${ }^{1}$ Cliona McGarvey ${ }^{*},{ }^{1}$ Karina Hamilton, ${ }^{1}$ Tom Matthews, ${ }^{1}$ Deirdre Devaney, ${ }^{2,1}$ Alf Nicholson. ${ }^{1}$ Temple St Children's University Hospital, Dublin, Ireland; ${ }^{2} R C S I$ Department of Paediatrics, Dublin, Ireland

\subsection{6/archdischild-2019-epa.229}

Background Injury is a leading cause of childhood death throughout the EU. For every fatality many more children are seriously injured and a large proportion left permanently disabled. Age specific, population based data is required to enable accurate assessment of the magnitude and characteristics of the injury problem.

Objective To determine the burden of accident and injury related childhood mortality in Ireland by determining the prevalence and characteristics of intentional and unintentional injury related deaths over a twelve year period from 2006 to 2017.

Design Retrospective review of cause of death information on all deaths $<15$ yrs, registered in Ireland from 2006-2017, with additional detailed information retrieved from autopsy reports reviewed by paediatric pathologists.

Results A total of 4,443 paediatric deaths ( $<15$ yrs) were registered in Ireland during 2006-2017, 49\% of which were aged $>28$ days. Beyond infancy the leading cause of childhood death during this period (26.5\%) was accident and injury. Most were unintentional accidents, children 1-4yrs being most susceptible (3.9/100,000 vs. 2.8/100,000 1-14yrs). Proportionate injury mortality increased gradually with age ranging from $<1 \%$ of neonatal deaths to $36 \%$ of deaths in children 10 14yrs. Road traffic accidents (RTA) accounted for the greatest proportion of accidental injury deaths across all ages (33\%). Other important causes of injury death in younger children 14yrs were drowning (8\%) fires/burns (7.2\%), high falls $(6.4 \%)$ and accidental strangulation (5.6\%), while fires/burns $(12.7 \%)$ and drowning (8.9\%) accounted for a greater proportion of deaths in children 5-9yrs. Interpersonal violence accounted for at least $9.5 \%$ of all injury deaths and $1.6 \%$ of child mortality overall. The rate of injury fatalities in children 1-14yrs has declined by $40 \%$ over the period from 2007 to 2016; from an average of 4.2 deaths $/ 100,000$ in 2007-2011 to 2.4 per 100,000 in 2012-2016, due largely to a significant decline in RTA fatalities during this period. A male preponderance of deaths was apparent for all categories of injury particularly drowning (88\%), accidental strangulation (75\%) and falls (69\%).

Conclusions Although welcome reductions in childhood mortality rates have been observed in Ireland in recent years, $26.5 \%$ of child deaths, attributable to accident and intentional injury are potentially avoidable and warrant further attention. National, age-specific data relating to the nature and circumstances of such deaths will assist in providing evidence based information with which to inform effective intervention strategies.

\section{GP169 THE POCKET-MONEY STUDY}

${ }^{1} \mathrm{~K}$ Flinn*, ${ }^{2} \mathrm{E}$ Healy, ${ }^{1} \mathrm{~A}$ O'Riordan, ${ }^{1} \mathrm{E}$ Fitzgerald, ${ }^{1} \mathrm{C}$ Lineen, ${ }^{1,2} \mathrm{C}$ O'Gorman, ${ }^{1} \mathrm{AM}$ Murphy. ${ }^{1}$ Department of Paediatrics, University Hospital Limerick, Limerick, Ireland; ${ }^{2}$ Graduate Entry Medical School, University Hospital Limerick, Limerick, Ireland

10.1136/archdischild-2019-epa.230
Background and aims Pocket-money is generally accepted to be a means for parents to introduce concepts of self-management, saving, budgeting and responsibility for their children. Much of the available published research focuses on the philosophical and sociological impact of pocket-money on the child's autonomy and on the dialogue between the parents' value systems or work ethic and how they confer this on their children.

Previous research has found that pocket-money is a simple way of preparing children for the future and creating more financially literate adults. ${ }^{1}$

From a paediatric-research viewpoint, pocket-money is considered a minor variable to be assessed when examining the broader picture of children's negative health habits.

There is a dearth of information available worldwide in either the medical literature or contemporary media on the amount children receive as pocket-money, how they spend it, how they should spend it and the consequences of the above.

Our objective was to investigate the practices of a cohort of modern-day parents in Ireland regarding the administration of pocket-money to their children in terms of ethos, amount, frequency and supervision.

We also explore the potential contribution a 'pocket money culture' makes to today's societal problems - obesity-pandemic, addiction-culture and materialism.

Methods A specifically designed questionnaire was administered to a random selection of 50 parents of children $(\leq 18$ years of age), attending our institution during August and September 2018. Data was compiled and analysed using Excel and SPSS.

Results A total of 50 questionnaires pertaining to 116 children (61 boys, 55 girls), were collected (4 fathers, 45 mothers, 1 grandmother). Only 19 guardians gave their children regular pocket money. Reasons cited were overall cost of living and a sense of already providing what is needed.

Conclusion To our knowledge it is the first study of its kind in Ireland. Further studies are needed to review changing mores with regard to pocket-money that may have arisen as result of the recession and the potential impact of this on parenting and childhood in Ireland.

\section{REFERENCES}

1. Sansone D, Rossi M, Fornero E. 'Four Bright Coins Shining at Me': Financial Education in Childhood, Financial Confidence in Adulthood. Journal of Consumer Affairs [Internet] 2018;. Available from: https://onlinelibrary.wiley.com/doi/abs/ 10.1111/joca.12207

\section{GP170 A SERIES OF SERIOUS SEQUELAE - A COLLECTION OF CASES OF CHICKENPOX COMPLICATIONS}

Aoife Cassidy*, Jacqueline McBrien. Temple Street Children's University Hospital, Dublin, Ireland

\subsection{6/archdischild-2019-epa.231}

Aim Primary infection with Varicella Zoster virus (VZV) results in 'chickenpox' - an acute illness involving a vesicular rash, fever and systemic symptoms. It is usually a disease of childhood and the majority of cases are benign and self-limiting. However, complications can be related to the virus or due to secondary bacterial infection. These complications can be associated with a high morbidity and high healthcare costs. 